\title{
Dynamic control of a SI engine with variable intake valve timing
}

\author{
Jun-Mo Kang ${ }^{1, *, \dagger}$ and J. W. Grizzle ${ }^{2,+}$ \\ ${ }^{1}$ EECS Department, University of Michigan, Ann Arbor, MI 48109-2122, USA \\ ${ }^{2} 4221$ EECS Bldg., 1301 Beal Ave., University of Michigan, Ann Arbor, MI 48109-2122, USA
}

\begin{abstract}
SUMMARY
Engines equipped with a means to actuate air flow at the intake valve can achieve superior fuel economy performance in steady state. This paper shows how modern nonlinear design techniques can be used to control such an engine over a wide range of dynamic conditions. The problem is challenging due to the nonlinearities and delays inherent in the engine model, and the constraint on the air flow actuator. The controller is designed on the basis of a mean-value model, which is derived from a detailed intake stroke model. The control solution has two novel features. Firstly, a recovery scheme for integrator wind-up due to input constraints is directly integrated into the nonlinear control design. The second novel feature is that the control Lyapunov function methodology is applied to a discrete-time model. The performance of the controller is evaluated and compared with a conventionally controlled engine through simulation on the detailed engine model. Copyright (C) 2003 John Wiley \& Sons, Ltd.
\end{abstract}

KEY WORDS: engines; discrete-time systems; nonlinear systems; Lyapunov methods

\section{INTRODUCTION}

In the design of an engine controller, one must optimize and make trade-offs between fuel economy, drivability (torque management) and emissions. Since an automobile must meet stringent federal emissions regulations in order to be sold, emissions control often is the most important factor. The customer, however, will consider fuel economy and torque response in making a selection.

The three way catalytic converter is the current technology for meeting emissions regulations. When operated near the stoichiometric point, emission conversion efficiencies of $98 \%$ for hydrocarbons, carbon monoxide and oxides of nitrogen can be achieved. However, as seen in Figure 1, deviations of \pm 0.2 air-fuel ratio $(A / F)$ will cause the conversion efficiency of at least

\footnotetext{
*Correspondence to: Dr. Jun-Mo Kang, General Motors R\&D, Mail Code 480-106-390 30500 Mound Road, PO Box 9055, Warren, MI 48090-9055, USA.

†E-mail: jun-mo.kang@gm.com

\$E-mail: grizzle@umich.edu
}

Contract/grant number: ECS-9631237.

Contract/grant sponsor: NSF GOALI;

Contract/grant sponsor: Ford Motor Company

Published online 3 January 2003

Copyright (C) 2003 John Wiley \& Sons, Ltd.

Received 12 October 2001 Accepted 7 March 2002 


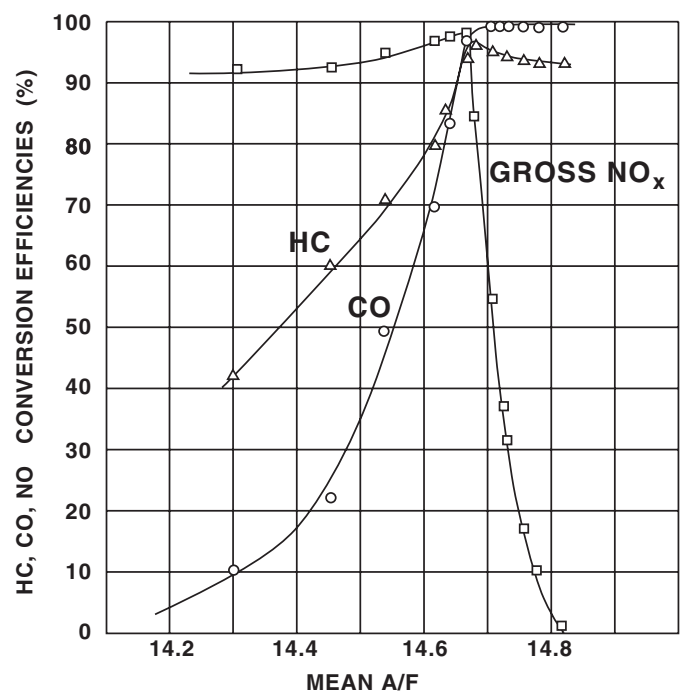

Figure 1. Steady-state conversion efficiency of TWC.

one of the emission components to drastically decrease. Thus an important control objective is to maintain the air-fuel ratio near stoichiometry.

In a standard spark ignition engine, the primary actuator is the fuel injector, which is typically located at the intake port. The mass flow rate of air entering the intake manifold is measured with a hot wire anemometer, and the fuel injected into the engine is adjusted to achieve a stoichiometric mixture; this is clearly a feedforward control action. In order to compensate for inevitable errors in air-fuel ratio, the air-fuel ratio is measured in the exhaust stream with an exhaust gas oxygen (EGO) sensor, and a PI feedback control loop is then used to achieve zero steady-state error for constant throttle position and engine speed.

Extensive research has been done to improve $A / F$ control performance of the system. Part of this research has focused on accurate estimation of transient air flow, thereby improving the accuracy of the feedforward controller. Another possibility is to control the air flow into the intake manifold with an electronic throttle $[1,2]$, or the air flow into the cylinders. This latter actuation can be achieved by adjusting the cam timing of the intake valves [3], by implementing independent electro-hydraulically controlled intake valves [4], by secondary (or port) throttles [5], or by using secondary valves in series with conventional intake valves [6]. The common element of these actuators is that they allow control of the air flow into the cylinders by adjusting the effective area of the intake valves. Three of these methods, namely variable intake cam timing, variable intake valve control, and series secondary valves can also be used to improve fuel economy. This is because, by controlling the breathing process of the engine, it is possible to raise the average manifold pressure, and thereby reduce pumping losses in the engine $[4,6]$.

The local aspects of joint air and fuel control have been studied in References [5,7] by designing a linear controller based around a specific operating point. The torque (drivability) and $A / F$ responses were superior or equal to that of a conventional engine (with fuel PI control) for small step changes in the primary throttle position. The major problem encountered with the linear analysis was that the resulting closed-loop system went unstable for large changes in the 
primary throttle position. This can be traced to two causes: the nonlinearities in the engine model and saturation in the air flow actuator.

This paper will attempt to address these issues by developing a more global control strategy. This design has two novel features. Firstly, an integrator anti-wind-up scheme is directly integrated into the nonlinear control design. The basic idea is to inject an extra reference signal to stabilize the integrator whenever the control inputs saturate, thereby avoiding integrator wind-up. The second novel feature is the application of the control Lyapunov functions (clf) methodology to a discrete-time model [8].

An overview of the engine model used in this study is presented in the next section. Control objectives are summarized in Section 3. The nonlinear control design is carried out in Section 4. A performance analysis via simulation is presented in Section 5. The controller design will be performed on a mean-value model, whereas its performance will be evaluated via simulation on a more detailed model which captures the air flow dynamics during an intake event.

\section{ENGINE MODEL}

\subsection{Breathing process model for un-actuated air flow}

The intake manifold representation considered here follows [9]. It is a continuous, nonlinear, $1.6 \mathrm{~L}$, four-cylinder model. Assuming constant intake manifold temperature, the intake breathing process of the conventional engine, based upon the ideal gas law and the conservation of mass, ${ }^{*}$ can be described by

$$
\begin{gathered}
\frac{\mathrm{d} p_{\mathrm{m}}}{\mathrm{d} t}=\frac{R T_{\mathrm{m}}}{V_{\mathrm{m}}}\left[W_{\phi}-\sum_{i=1}^{4} W_{\mathrm{c}_{i}}\right] \\
\frac{\mathrm{d} p_{\mathrm{c}_{i}}}{\mathrm{~d} t}=\frac{1}{V_{\mathrm{c}_{i}}}\left[R T_{\mathrm{c}} W_{\mathrm{c}_{i}}-\dot{V}_{\mathrm{c}_{i}} p_{\mathrm{c}_{i}}\right], \quad i=1, \ldots, 4
\end{gathered}
$$

where, $p_{\mathrm{m}}$ is the intake manifold pressure and $p_{\mathrm{c}_{i}}$ is the pressure in the $i$ th cylinder, $W_{\phi}$ and $W_{\mathrm{c}_{i}}$ are the mass air flow rate into the manifold and that pumped out of the manifold into the $i$ th cylinder, respectively. $V_{\mathrm{m}}$ and $V_{\mathrm{c}_{i}}$ are the volume of the intake manifold and that of the $i$ th cylinder, $R$ is the specific gas constant, $T_{\mathrm{m}}$ is the intake manifold temperature, and $T_{\mathrm{c}}$ is the cylinder wall temperature during the intake event. The $i$ th cylinder volume is approximated as a function of crank-angle: ${ }^{\dagger}$

$$
\begin{gathered}
V_{\mathrm{c}_{i}}(\theta)=\frac{V_{\mathrm{d}}}{2}\left(1-\cos \left(\theta-\frac{720}{4}(i-1)\right)\right)+V_{\mathrm{cl}} \\
\theta=\left(\int_{0}^{t} \frac{N}{60} 360 \mathrm{~d} \tau\right) \bmod 720^{\circ}
\end{gathered}
$$

where $V_{\mathrm{d}}$ is the maximum cylinder displaced volume, $V_{\mathrm{cl}}$ is the cylinder clearance volume, $\theta$ is crank-angle in degrees, and $N$ is the engine speed in RPM. The quantity $p_{\mathrm{c}_{i}}$ in (2) is initialized to the exhaust pressure $(110 \mathrm{kPa})$ at the intake valve open timing (IVO), assuming that cylinder pressure reaches equilibrium at exhaust manifold pressure before intake valve opens. The mass

\footnotetext{
* See Appendix B for specific parameter values and units used in the study.

${ }^{\dagger}$ See Reference [10] for exact representation.
} 
air flow into the manifold, $W_{\phi}$, is approximated as a function of upstream pressure $\left(p_{0}\right)$ and the downstream pressure, which is manifold pressure. Upstream pressure is assumed to be atmospheric (i.e. $p_{0}=100 \mathrm{kPa}$ ):

$$
\begin{gathered}
W_{\phi}=1000 \times A_{\phi}(\phi) d\left(p_{\mathrm{m}}, p_{0}\right) \\
A_{\phi}(\phi)=1.268 \times 10^{-4}\left(-0.2215-2.275 \phi+0.23 \phi^{2}\right) \\
d\left(p_{\mathrm{m}}, p_{0}\right)= \begin{cases}1 & \text { if } p_{\mathrm{m}} \leqslant p_{0} / 2 \\
2 / p_{0} \sqrt{p_{\mathrm{m}} p_{0}-p_{\mathrm{m}}^{2}} & \text { if } p_{\mathrm{m}}>p_{0} / 2\end{cases}
\end{gathered}
$$

where $A_{\phi}(\phi)$ is the effective area of the throttle body, as a function of primary throttle angle $(\phi)$ in degrees. The mass air flow into the $i$ th cylinder, $W_{\mathrm{c}_{i}}$, is expressed as ${ }^{*}$

$$
W_{\mathrm{c}_{i}}=1000 \times A_{\mathrm{v}}\left(L_{\mathrm{v}_{i}}\right) d\left(p_{\mathrm{c}_{i}}, p_{\mathrm{m}}\right)
$$

where $A_{\mathrm{V}}$ is the effective area of an intake valve, which is modelled as a linear function of valve lift $(\mathrm{mm}), L_{\mathrm{v}_{i}}$,

$$
A_{\mathrm{v}}\left(L_{\mathrm{v}_{i}}\right)=\alpha L_{\mathrm{v}_{i}}
$$

The scale factor $\alpha$ is identified as 0.0175 in Reference [9] for the experimental engine under consideration.

The valve lift motion is characterized by open timing (IVO), maximum lift (IVL), and open duration (IVD). For a conventional engine, the valve lift is a sinusoidal function of these parameters and crank-angle during an intake event [9]:

$$
L_{\mathrm{V}_{i}}(\theta)=\operatorname{IVL} \sin ^{2}\left(\frac{180}{\mathrm{IVD}}(\theta-90(i-1)-\mathrm{IVO})\right)
$$

In this study, the valve specifications in Reference [9] are used: IVO $=-8^{\circ}, \mathrm{IVL}=8.1 \mathrm{~mm}$, and $\operatorname{IVD}=234^{\circ}$.

\subsection{Mean-valued breathing process model}

The above model describes the evolution of the various pressures and mass flow rates of the breathing process within an engine event. In general, for control design purposes, it is preferable to adopt a phenomenological, mean-valued model by averaging pressures and mass flow rates over an engine event $[3,11]$. This typically results in a simpler model and one where the time scales are better adapted to those of the actuation processes. For these reasons, the mass air flow rate into the cylinder, (8), is first averaged based on simulation results, and then, via regression, represented as a function of manifold pressure and engine speed $N$ as

$$
\begin{aligned}
W_{\mathrm{c}}\left(p_{\mathrm{m}}, N\right)= & -1.7474 \times 10^{-3}+5.6837 \times 10^{-6} p_{\mathrm{m}}-1.6529 \times 10^{-3} N \\
& +1.5666 \times 10^{-7} N p_{\mathrm{m}}
\end{aligned}
$$

For validation, Figure 3 compares the averaged mass air flow rate $W_{\mathrm{c}_{i}}$ with constant manifold pressure and engine speed against the regression model (11).

\footnotetext{
The model is valid as long as the air momentum is insignificant, which becomes visible at very high engine speed. 


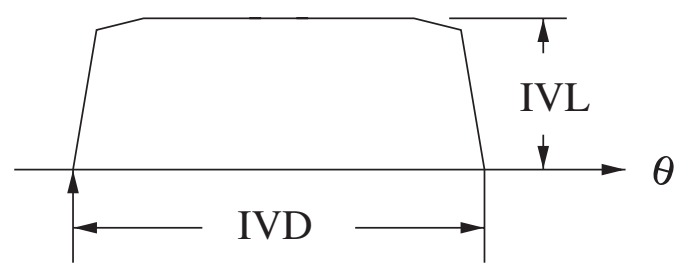

IVO

Figure 2. Profile of hydraulically actuated valve.

\subsection{Cylinder air charge control}

To account for air flow actuation, the mass flow rate into the cylinder is modified as follows

$$
W_{\mathrm{a}}=\beta W_{\mathrm{c}}
$$

where $\beta$ represents the normalized linear scale factor of mass air flow rate, and is limited between* 0.1 and 1 . This results in the mean-value breathing process model

$$
\frac{\mathrm{d} p_{\mathrm{m}}}{\mathrm{d} t}=\frac{R T_{\mathrm{m}}}{V_{\mathrm{m}}}\left(W_{\phi}-\beta W_{\mathrm{c}}\right)
$$

Depending on the air charge actuation scheme used, more or less manipulation may be necessary to put the model in this form. This will be discussed shortly. However, each scheme has the qualitative feature of being able to increase or decrease the air admitted into the cylinder, over a certain range.

On a practical basis, the choice of the particular air charge actuation scheme will be based on many factors. For example, in view of fuel economy, control of the cylinder air charge via intake valve open timing or intake valve open duration reduces pumping losses by allowing increased intake port pressure, which is essentially equivalent to intake manifold pressure [4]. On the other hand, secondary throttles choke the air flow at the intake ports, thereby decreasing the intake port pressure, which results in increased pumping losses [10]. Other issues such as reliability and cost must also be considered. From the control point of view taken in this paper, the primary difference between the various schemes lies in the speed of response of the associated actuator dynamics. The analysis carried out in this paper is valid for any actuation scheme that can be modelled by (12) with an actuator response that is essentially instantaneous with respect to the time duration of an engine event. For definiteness, this paper assumes a hydraulically actuated cam, whose valve motion profile is depicted in Figure 2.

The key concept is to control the air flow by independently adjusting three parameters IVO, IVL, and IVD of the intake valve motion. The cylinder air charge, $m_{\mathrm{a}_{i}}(g)$, is then determined as

\footnotetext{
*The lower bound of $\beta$ should be determined to avoid misfire owing to lack of oxygen in the mixture.
} 


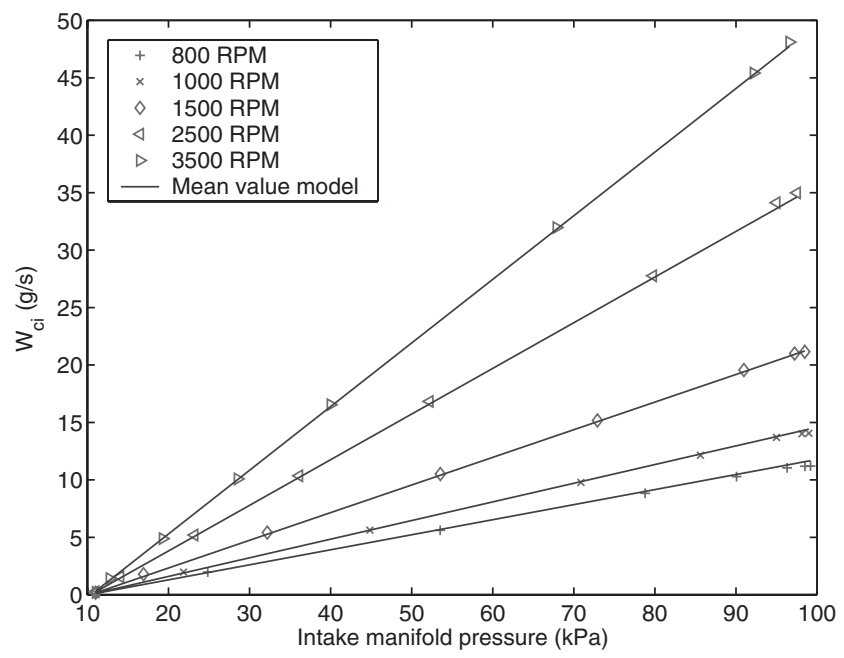

Figure 3. Comparison between averaged mass air flow rate $W_{\mathrm{c}_{i}}$ and the $W_{\mathrm{c}}$ from regression model.

a function of these parameters via

$$
\begin{aligned}
m_{\mathrm{a}_{i}}= & \frac{60}{360} \int_{\mathrm{IVO}}^{\mathrm{IVO}+\mathrm{IVD}} W_{\mathrm{c}_{i}} \frac{1}{N} \mathrm{~d} \theta=\frac{60}{360} \int_{\mathrm{IVO}}^{\mathrm{IVO}+\mathrm{IVD}}= \\
& A_{\mathrm{V}}\left(L_{\mathrm{V}_{i}}(\mathrm{IVL}, \theta)\right) \mathrm{d}\left(p_{\mathrm{c}_{i}}, p_{\mathrm{m}}\right) \frac{1}{N} \mathrm{~d} \theta
\end{aligned}
$$

For simplicity in this study, IVO and IVL are fixed at top dead centre and $8 \mathrm{~mm}$, respectively, leaving IVD as the unique control parameter. As an example, Figure 4 shows a typical mass air flow rate curve as a function of IVD, with respect to crank-angle. Then $\mathrm{IVD}_{\beta}$, which is defined to be the intake valve open timing which approximately achieves

$$
m_{\mathrm{a}_{i}}=\frac{60}{360} \int_{\mathrm{IVO}}^{\mathrm{IVO}+\mathrm{IVD}_{\beta}} A_{\mathrm{v}}\left(L_{\mathrm{v}_{i}}(\theta)\right) \mathrm{d}\left(p_{\mathrm{c}_{i}}, p_{\mathrm{m}}\right) \frac{1}{N} \mathrm{~d} \theta \approx \beta W_{\mathrm{c}} T
$$

where $T$ is the time taken for the piston to travel from top dead centre (TDC) to bottom dead centre (BDC), can be determined through simulation, and mapped as a function of engine speed and intake manifold pressure.

\subsection{Mean-value feedgas and torque model}

The discrete-event nature of the combustion process introduces transport delays, which are dependent on engine speed. This motivates discretizing the overall model synchronously with engine events $[12,13]$. That is, the independent variable is transformed from time to crank-angle, and the model is then discretized at a constant rate in the crank-angle domain. Here, the model is discretized with period $\pi$ radians in crank-angle, which corresponds to one engine event (elapsed time of revolution for the intake stroke, for example). This procedure introduces speeddependent terms in the dynamics, but it permits standard stability analysis to be applied. 


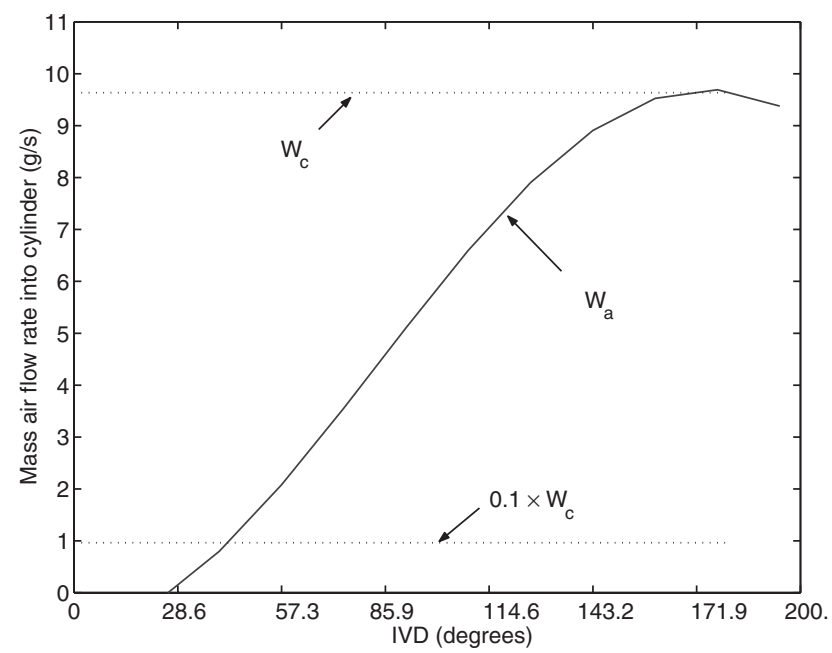

Figure 4. Mass air flow rate into cylinder as a function of IVD at constant engine speed 1200 RPM and intake manifold pressure $60 \mathrm{kPa}$.

The calculation delay in the injection of fuel and the transport delays are included in the model. The dynamics of the EGO sensor is modeled by a first-order difference equation; in the time domain, its time constant is $0.20 \mathrm{~s}$.

The steady state engine torque is affected by many parameters such as ignition delay, EGR and so on. The general relations between these parameters and engine torque are derived from experimental data and curve fitting methods. Unfortunately, a torque model for the engine in consideration [9] is not available at this moment, and for this reason, that of Reference [11] is adopted in the model

$$
\begin{aligned}
T_{\mathrm{b}}= & -181.3+379.36 m_{\mathrm{a}}+21.91(A / F)-0.85(A / F)^{2}+0.26 \sigma_{\mathrm{s}}-0.0028 \sigma_{\mathrm{s}}^{2} \\
& +0.0027 N-0.00000107 N^{2}+0.000048 N \sigma_{\mathrm{s}}+2.55 \sigma_{\mathrm{s}} m_{\mathrm{a}} \\
& -0.05 \sigma_{\mathrm{s}}^{2} m_{\mathrm{a}}+2.36 \sigma_{\mathrm{s}} m_{\mathrm{e}}
\end{aligned}
$$

where $m_{\mathrm{a}}$ is the mass air charge (g/intake event), $A / F$ the air-fuel ratio, $N$ the engine speed $(\mathrm{RPM}), m_{\mathrm{e}}$ the EGR (g/intake event) and $\sigma_{\mathrm{s}}$ degrees of spark advance before top dead centre.

Since the focus of this work is on utilizing innovative air actuation, conventional variables such as EGR and spark advance are assumed to be constant for simplicity. The above model was identified [11] at air-fuel ratios between 13.6 and 15.6, engine speeds between 800 and $6000 \mathrm{RPM}$, intake manifold pressures between 35 and $100 \mathrm{kPa}$, and torque from 14 to $135 \mathrm{Nm}$.

The complete block diagram of the feedgas and torque model is shown in Figure 5, and that of the overall engine model is shown in Figure 6. 


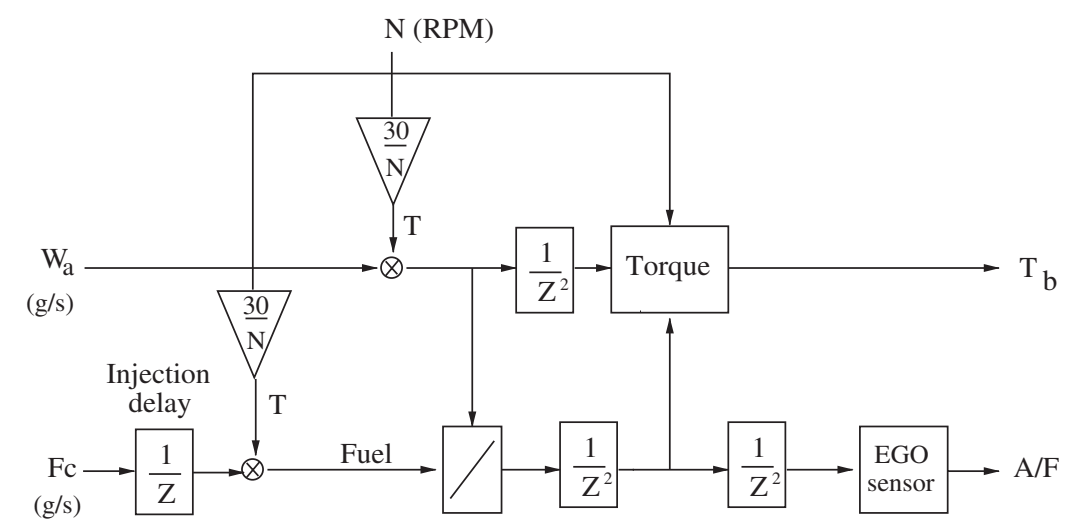

Figure 5. Feedgas and torque model.

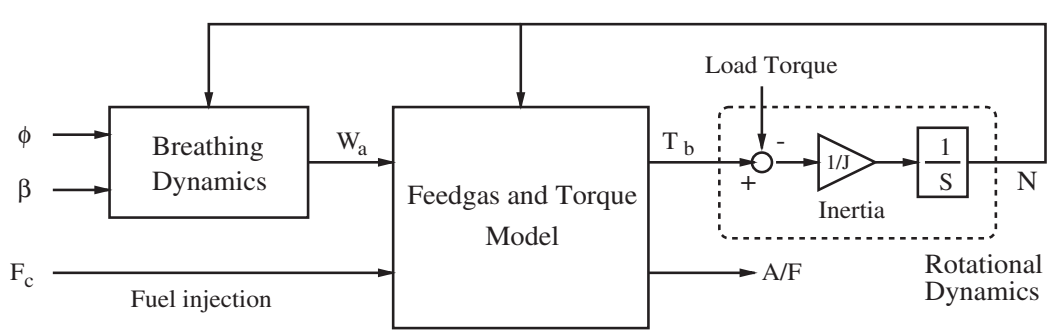

Figure 6. The block diagram of overall engine model.

\section{CONTROL PROBLEM DESCRIPTION}

The major objectives of the control design are:

1. exploit the air flow actuation capability to achieve higher manifold pressure, thereby reducing pumping losses and improving fuel economy;

2. achieve a torque response that is as similar as possible to a conventional engine so that there is no perceptible loss in drivability;

3. minimize air-fuel ratio excursions from stoichiometry to maximize the simultaneous conversion efficiency of the catalyst, thereby minimizing overall emissions.

The control inputs are effective valve area factor, $\beta$, and (amount of) fuel injection, $F_{\mathrm{c}}$. It is assumed that the air-fuel ratio is measured by a linear EGO sensor placed in the exhaust stream, just ahead of the catalyst. In addition, it is assumed that some means of measuring torque is available.*

As stated, the problem has two-inputs, two-measured outputs and three performance objectives. This imbalance is treated by 'squaring down' the performance objectives. At stoichiometry, torque depends primarily on mass air flow. At low primary throttle angle, a static

*Currently, several major automotive suppliers are developing sensors for direct measurement of engine torque; for the use of such sensors in high-performance applications, see Reference [14]. 


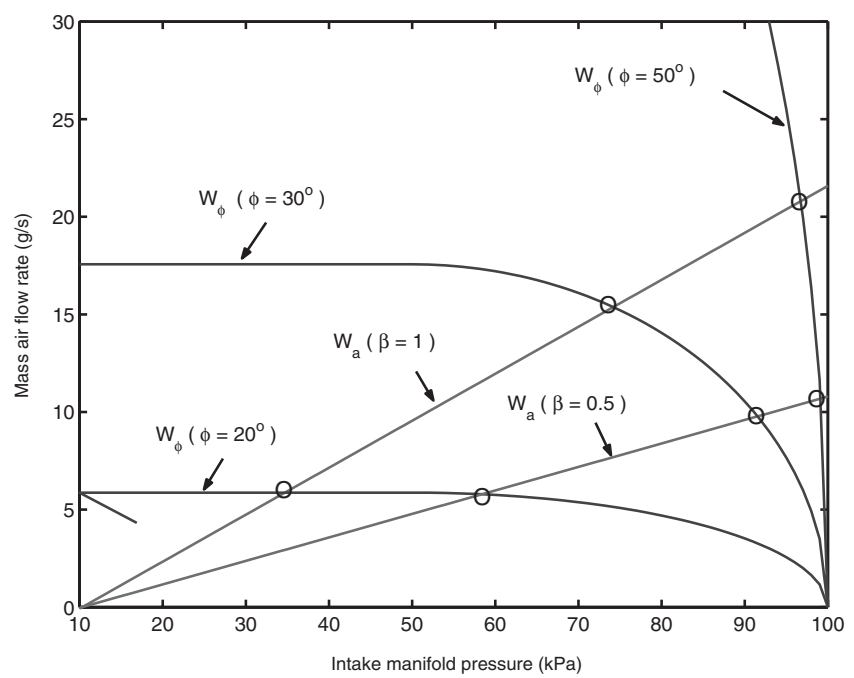

Figure 7. Steady-state mass air flow rate corresponding to the scale factor $\beta$ at primary throttle angles of $20^{\circ}, 30^{\circ}$ and $50^{\circ}$, and an engine speed of $1500 \mathrm{RPM}$.

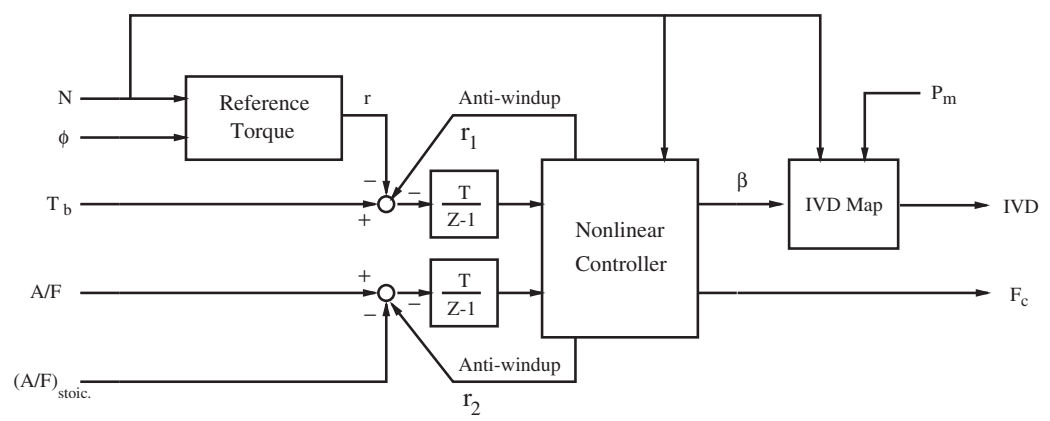

Figure 8. Controller structure.

mass air flow model is constructed so as to closely match the steady-state torque of the joint-airand-fuel-controlled engine to that of the conventional engine, while maintaining the intake manifold pressure greater than $50 \mathrm{kPa}$, in steady state. This also guarantees control authority over cylinder mass air flow rate [5]; see Figure 7. In this regime, the parameter $\beta$ is near 0.5-0.6. At high primary throttle angles, the manifold pressure is already high in a conventional engine, and hence, the static mass air flow model is simply designed to closely match the steady-state torque of the conventional engine. The static mass air flow model, and hence the static torque model as well, is a function of the primary throttle angle and engine speed.

The control problem is now defined as in Figure 8: the objective is to design a controller that achieves zero steady-state error in commanded torque and stoichiometric air-fuel ratio for constant primary throttle position, while avoiding integrator wind-up. The commanded torque is taken to be a low pass filtered version of the static torque model. The time constant of a first- 


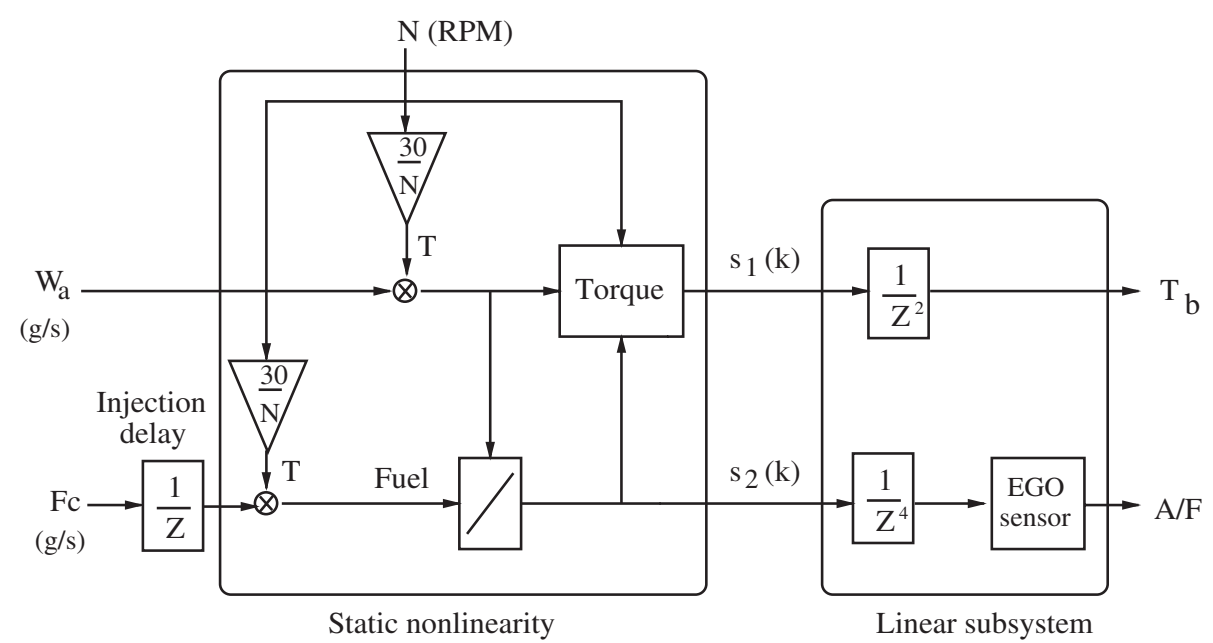

Figure 9. Equivalent feedgas and torque model.

order low-pass filter, $\tau_{\mathrm{r}}$, is to be determined to trade off drivability (speed of torque response) with emissions (deviations in air-fuel ratio from stoichiometry).

\section{NONLINEAR FEEDBACK CONTROL DESIGN}

This section follows a recent approach to the design of nonlinear controllers, namely control Lyapunov functions* (clf). In particular, a Hammerstein-like equivalent model of the feedgas and torque model is introduced and a nonlinear feedback controller is developed based on a positive semi-definite clf. This allows a systematic design procedure for a state feedback controller, and an observer for implementing the state feedback controller. First, a simple state feedback controller is designed based on the intake manifold dynamics plus the nonlinear portion of the Hammerstein-like model, and then the controller is extended to include the linear subsystem. Finally, an asymptotic observer is designed, and stability of the resulting closed-loop system is discussed.

One of the novelties in this work is the use of control Lyapunov functions on a discrete-time system model. Most of the work in this area has focused on continuous-time models.

\subsection{State feedback control}

The feedgas and torque model of Figure 5 includes delays and nonlinearities (air-fuel division and torque generation). In the sense of input-output equivalence, it can be rearranged to an equivalent Hammerstein model with a delayed input, as shown in Figure 9. The feedgas and torque model is then a delay plus a static nonlinearity followed by a decoupled linear subsystem.

\footnotetext{
*The term is being used in an extended sense because the candidate Lyapunov function will not be positive definite. Consequently, universal formulas for stabilizing feedbacks, such as Sontag's formula, [15], are not applicable.
} 
To fix the main ideas of the clf design, a controller is first designed for an engine model consisting of the intake manifold dynamics followed by the injection delay and static nonlinearity of the feedgas and torque model (the linear subsystem will be initially ignored). The control signals are effective valve area factor, $\beta$, and $\zeta$, which is the inverse (amount of) fuel flow rate $(\mathrm{s} / \mathrm{g})$. To aid in the feedback design, the torque generation equation (16) is linearized around stoichiometry. Since $\beta$ is limited by 0.1 and 1 , and the fuel injection rate is practically constrained (from 0.01 to $20 \mathrm{~g} / \mathrm{s}$ ), discrete state equations are given by

$$
\begin{gathered}
p_{\mathrm{m}}(k+1)=p_{\mathrm{m}}(k)+\frac{R T_{\mathrm{m}}}{V_{\mathrm{m}}} T\left(W_{\phi}\left(p_{\mathrm{m}}(k), N\right)-\mathrm{sat}_{0.1}^{1}(\beta) W_{\mathrm{c}}\left(p_{\mathrm{m}}(k), N\right)\right) \\
x_{1}(k+1)=\operatorname{sat}_{0.05}^{100}(\zeta) \\
T_{\mathrm{b}}(k)=410.86 T W_{\mathrm{c}}\left(p_{\mathrm{m}}(k), N\right) \operatorname{sat}_{0.1}^{1}(\beta)-2.98\left(x_{1}(k) W_{\mathrm{c}}\left(p_{\mathrm{m}}(k), N\right) \mathrm{sat}_{0.1}^{1}(\beta)-A / F_{\mathrm{s}}\right) \\
\quad+\psi(N) \\
A / F(k)=x_{1}(k) W_{\mathrm{c}}\left(p_{\mathrm{m}}(k), N\right) \mathrm{sat}_{0.1}^{1}(\beta)
\end{gathered}
$$

where $x_{1}$ is the delayed fuel injection, $T$ the intake event duration, $A / F_{\mathrm{s}}$ the stoichiometric air-fuel ratio and $\psi(N)=-37.44+0.00414 N-0.00000107 N^{2}$. The saturation function is defined as

$$
\operatorname{sat}_{b}^{a}(u)= \begin{cases}a & \text { if } u \geqslant a \\ u & \text { if } b<u<a \\ b & \text { if } b \geqslant u\end{cases}
$$

Figure 10 shows that the approximation error between (16) and the linearized torque is less than $1 \mathrm{Nm}$ for air-fuel ratios between 13.6 and 15.6, where the torque model was identified in Reference [11].

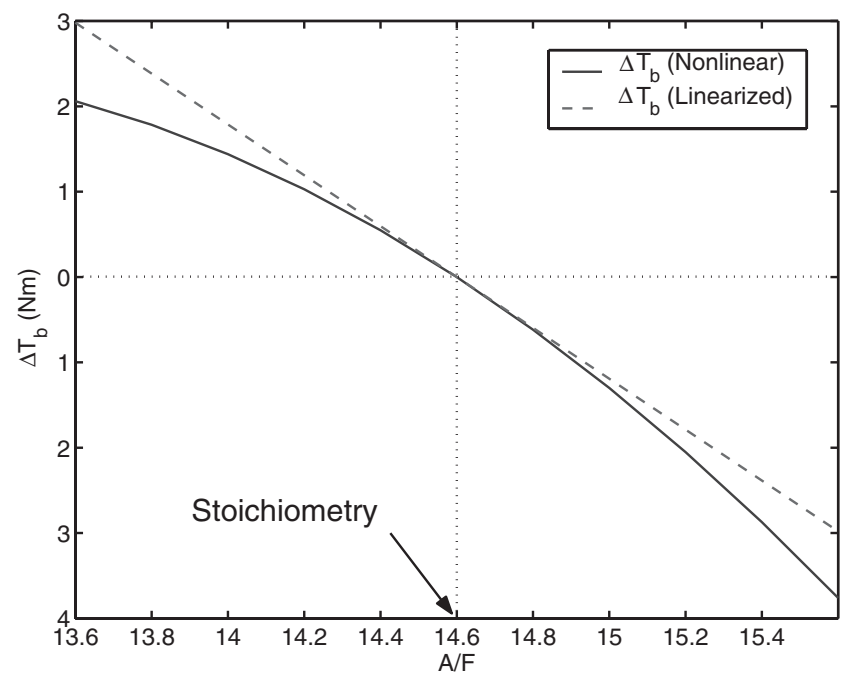

Figure 10. Torque deviation from nominal torque given mass air charge and engine speed. 
Due to the constraints on the inputs, an integrator anti-wind-up scheme needs to be integrated into the controller design. The key idea used here is to actively adjust the reference signals in order to stabilize the integrators. The difference equations of the integrators are modified to include reference adjustment as follows:

$$
\begin{gathered}
q_{1}(k+1)=q_{1}(k)+T\left(T_{\mathrm{b}}(k)-r-r_{1}(k)\right) \\
q_{2}(k+1)=q_{2}(k)+T\left(A / F(k)-A / F_{\mathrm{s}}-r_{2}(k)\right)
\end{gathered}
$$

where $r$ is the reference torque $(\mathrm{Nm})$, as a function of primary throttle angle $(\phi)$ and engine speed $(N)$ and $r_{1}, r_{2}$ the reference signal adjustments that are to be determined.

Since $q_{1}(k+1)$ and $q_{2}(k+1)$ have common terms, it is natural to choose a candidate Lyapunov function as

$$
V_{L 1}=V_{1}^{2}=\left(q_{1}+2.98 q_{2}\right)^{2}
$$

so that these two states are bounded relative to one another; that is, if one of them is bounded, then so is the other. In the next step, another candidate Lyapunov function with parameter $\kappa$ is chosen to force one of the integrator states, $q_{2}$, to be bounded relative to the state $x_{1}$ :

$$
V_{L 2}=V_{2}^{2}=\left(\kappa q_{2}+x_{1}\right)^{2}
$$

Thus, because $p_{\mathrm{m}}$ is always bounded, if it can later be proven that any one of $x_{1}, q_{1}$ or $q_{2}$ is bounded, then all of the states are bounded.

A composite, quadratic, positive semi-definite Lyapunov function is then given by

$$
V_{L}(x)=V_{L 1}(x)+V_{L 2}(x)=V_{1}^{2}(x)+V_{2}^{2}(x) \geqslant 0 \quad \text { where } x=\left(p_{\mathrm{m}}, x_{1}, q_{1}, q_{2}\right)
$$

The difference equation can be computed to be

$$
\begin{aligned}
\Delta V_{L}(x(k))= & \left(V_{1}^{2}(x(k+1))-V_{1}^{2}(x(k))\right)+\left(V_{2}^{2}(x(k+1))-V_{2}^{2}(x(k))\right) \\
= & \left(V_{1}(x(k+1))-V_{1}(x(k))\right)\left(V_{1}(x(k+1))+V_{1}(x(k))\right) \\
& +\left(V_{2}(x(k+1))-V_{2}(x(k))\right)\left(V_{2}(x(k+1))+V_{2}(x(k))\right)
\end{aligned}
$$

where

$$
\begin{aligned}
V_{1}(x(k+1))-V_{1}(x(k))= & T\left(410.86 T W_{\mathrm{c}}\left(p_{\mathrm{m}}(k), N\right) \mathrm{sat}_{0.1}^{1}(\beta)-2.98 r_{2}(k)\right. \\
& \left.+\psi(N)-r-r_{1}(k)\right) \\
V_{2}(x(k+1))-V_{2}(x(k))= & \kappa T\left(x_{1}(k) W_{\mathrm{c}}\left(p_{\mathrm{m}}(k), N\right) \mathrm{sat}_{0.1}^{1}(\beta)-A / F_{\mathrm{s}}-r_{2}(k)\right) \\
& +\operatorname{sat}_{0.05}^{100}(\zeta)-x_{1}(k)
\end{aligned}
$$

The control signals are designed as

$$
\begin{aligned}
& \beta(x)=\frac{1}{410.86 T W_{\mathrm{c}}\left(p_{\mathrm{m}}, N\right)}\left(-\psi(N)+r-\frac{c_{1}}{T} V_{1}(x)\right) \\
& \zeta(x)=-\kappa T\left(x_{1} W_{\mathrm{c}}\left(p_{\mathrm{m}}, N\right) \mathrm{sat}_{0.1}^{1}(\beta(x))-A / F_{\mathrm{s}}\right)+x_{1}-c_{2} V_{2}(x)
\end{aligned}
$$


so that

$$
\begin{aligned}
& V_{1}(x(k+1))-V_{1}(x(k))=-c_{1} V_{1}(x(k)) \\
& V_{2}(x(k+1))-V_{2}(x(k))=-c_{2} V_{2}(x(k))
\end{aligned}
$$

With $0<c_{1}<2$ and $0<c_{2}<2$, this achieves $\Delta V_{L}(x)$ negative semi-definite if the control signals are within the constraints

$$
\Delta V_{L}(x)=-c_{1}\left(2-c_{1}\right) V_{1}^{2}(x)-c_{2}\left(2-c_{2}\right) V_{2}^{2}(x) \leqslant 0
$$

If the control signals exceed their constraints, $r_{1}$ and $r_{2}$ become active and are designed as

$$
\begin{gathered}
r_{1}=410.86 T W_{\mathrm{c}}\left(p_{\mathrm{m}}, N\right) \mathrm{sat}_{0.1}^{1}(\beta)-2.98 r_{2}+\psi(N)-r+\frac{c_{1}}{T} V_{1}(x) \\
r_{2}=x_{1} W_{\mathrm{c}}\left(p_{\mathrm{m}}, N\right) \mathrm{sat}_{0.1}^{1}(\beta)-A / F_{\mathrm{s}}+\frac{1}{\kappa T}\left(\operatorname{sat}_{0.05}^{100}(\zeta)-x_{1}+c_{2} V_{2}(x)\right)
\end{gathered}
$$

so that (30) is consistently preserved regardless of the input constraints. Note that if the control signals satisfy their constraints, $r_{1}$ and $r_{2}$ are zero and do not affect the integrators. The goal now is to understand what (30) implies about the stability of the closed-loop system. When $\Delta V_{L} \equiv 0, V_{1} \equiv V_{2} \equiv 0$ from (30) and the control signals become

$$
\begin{aligned}
& \beta_{\Delta V_{L}=0}=\frac{1}{410.86 T W_{\mathrm{c}}\left(p_{\mathrm{m}}, N\right)}(-\psi(N)+r) \\
& \zeta_{\Delta V_{L}=0}=\left(1-\kappa T W_{\mathrm{c}}\left(p_{\mathrm{m}}, N\right) \mathrm{sat}_{0.1}^{1}\left(\beta_{\Delta V_{L}=0}\right)\right) x_{1}+\kappa T A / F_{\mathrm{s}}
\end{aligned}
$$

Then, given constant primary throttle angle and constant engine speed, the discretized, meanvalue breathing dynamics (13) is asymptotically stable in the sense of Lyapunov with control signal (33) if the sampling rate is sufficiently fast. To show this, mass air flow rate $W_{\phi}$ and $\operatorname{sat}_{0.1}^{1}\left(\beta_{\Delta V_{L}=0}\right) \times W_{\mathrm{c}}$ are shown in Figure 11, along with the equilibrium intake manifold pressure, denoted as $p_{\mathrm{s}}$. The discrete breathing dynamics can be expressed as

$$
\begin{aligned}
p_{\mathrm{e}}(k+1) & =p_{\mathrm{e}}(k)+\frac{R T_{\mathrm{m}}}{V_{\mathrm{m}}} T\left(W_{\phi}\left(p_{\mathrm{e}}(k)+p_{\mathrm{s}}\right)-\operatorname{sat}_{0.1}^{1}\left(\beta_{\Delta V_{L}=0}\right) W_{\mathrm{c}}\left(p_{\mathrm{e}}(k)+p_{\mathrm{s}}\right)\right) \\
& =p_{\mathrm{e}}(k)+f\left(p_{\mathrm{e}}(k)\right)
\end{aligned}
$$

where $p_{\mathrm{e}}(k)=p_{\mathrm{m}}(k)-p_{\mathrm{s}}$. A candidate positive definite Lyapunov function for $p_{\mathrm{e}}$ is

$$
V_{p}\left(p_{\mathrm{e}}\right)=p_{\mathrm{e}}^{2}>0
$$

whose difference equation is

$$
\begin{aligned}
\Delta V_{p}\left(p_{\mathrm{e}}(k)\right) & =\left(p_{\mathrm{e}}(k+1)-p_{\mathrm{e}}(k)\right)\left(p_{\mathrm{e}}(k+1)+p_{\mathrm{e}}(k)\right) \\
& =f\left(p_{\mathrm{e}}(k)\right)\left(2 p_{\mathrm{e}}+f\left(p_{\mathrm{e}}(k)\right)\right)
\end{aligned}
$$

Since $f\left(p_{\mathrm{e}}\right)$ is a static nonlinearity lying in the second and fourth quadrants, and $\left|2 p_{\mathrm{e}}\right|>\left|f\left(p_{\mathrm{e}}\right)\right|$ if the sampling rate is sufficiently fast, ${ }^{*}$ it can be shown that $2 p_{\mathrm{e}}+f\left(p_{\mathrm{e}}\right)$ lies in the first and third

\footnotetext{
*The sampling period used here of one revolution of the crankshaft can be easily decreased, if necessary [16].
} 


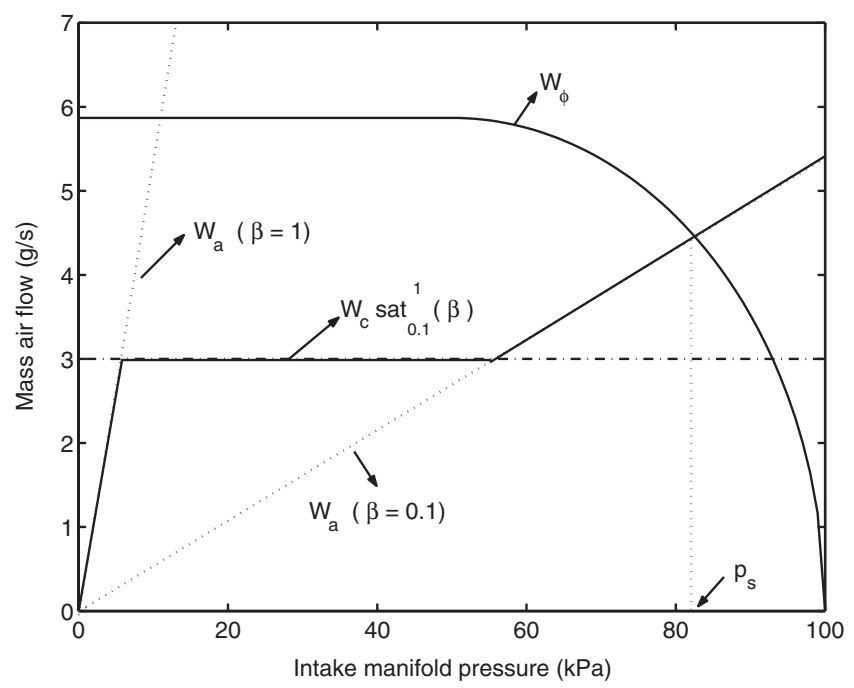

Figure 11. Mass air flow rate at a primary throttle angle of $20^{\circ}$, and an engine speed of $3500 \mathrm{RPM}$.

quadrants. Thus $\Delta V_{p}\left(p_{\mathrm{e}}\right)$ is negative definite, which proves asymptotic stability of $p_{\mathrm{m}}$ in the sense of Lyapunov.

With control signals (33) and (34), the state $x_{1}$ evolves as

$$
x_{1}(k+1)=\operatorname{sat}_{0.05}^{100}\left(\left(1-\kappa T W_{\mathrm{c}}\left(p_{\mathrm{m}}(k), N\right) \mathrm{sat}_{0.1}^{1}\left(\beta_{\Delta V_{L}=0}\right)\right) x_{1}(k)+\kappa T A / F_{\mathrm{s}}\right)
$$

The parameter $\kappa$ is now chosen so that

$$
\left|1-\kappa T W_{\mathrm{c}}\left(p_{\mathrm{m}}, N\right) \operatorname{sat}_{0.1}^{1}\left(\beta_{\Delta V_{L}=0}\right)\right|<1
$$

in order that $x_{1}$ be asymptotically stable in the sense of Lyapunov. Since $V_{1} \equiv V_{2} \equiv 0$ in the manifold $W=\left\{x \mid \Delta V_{L}(x)=0\right\},(20)$ and (21) imply asymptotic stability in the sense of Lyapunov of the integrator states. Then by Reference [8], the closed-loop system is stable in the sense of Lyapunov, since it is asymptotically stable in the manifold $Z=\left\{x \mid V_{L}(x)=0\right\}$, which is equal to $W$. This also proves asymptotic stability since all states are bounded and approach $W$ by LaSalle's Theorem [17].

\section{Remark}

Suppose that in steady state, the inverse amount of fuel injection, $\zeta$, is not saturated (i.e. it is within its allowed constraints). Then from (27) and (32), $r_{2} \equiv 0$. Thus, the steady-state air-fuel ratio will be at the stoichiometric value. Moreover, if $\beta$ is also within its constraints in steady state, (26) and (31) imply that $r_{1} \equiv 0$, and thus the steady-state torque will be the desired value. In other words, if the actuators are not saturated in steady state, the steady-state error is zero. 
The above idea can be easily extended to the full order model. The complete state equations of the feedgas and torque model shown in Figure 9 are given by

$$
\begin{aligned}
p_{\mathrm{m}}(k+1)= & p_{\mathrm{m}}(k)+\frac{R T_{\mathrm{m}}}{V_{\mathrm{m}}} T\left(W_{\phi}\left(p_{\mathrm{m}}(k), N\right)-\operatorname{sat}_{0.1}^{1}(\beta) W_{\mathrm{c}}\left(p_{\mathrm{m}}(k), N\right)\right) \\
x_{1}(k+1)= & \operatorname{sat}_{0.05}^{100}(\zeta) \\
x_{2}(k+1)= & x_{1}(k) W_{\mathrm{c}}\left(p_{\mathrm{m}}(k), N\right) \mathrm{sat}_{0.1}^{1}(\beta) \\
x_{3}(k+1)= & x_{2}(k) \\
x_{4}(k+1)= & x_{3}(k) \\
x_{5}(k+1)= & x_{4}(k) \\
x_{6}(k+1)= & \left(1-\frac{T}{\tau_{\mathrm{s}}}\right) x_{6}(k)+\frac{T}{\tau_{\mathrm{s}}} x_{5}(k) \\
x_{7}(k+1)= & 410.86 T W_{\mathrm{c}}\left(p_{\mathrm{m}}(k), N\right) \mathrm{sat}_{0.1}^{1}(\beta) \\
& -2.98\left(x_{1}(k) W_{\mathrm{c}}\left(p_{\mathrm{m}}(k), N\right) \mathrm{sat}_{0.1}^{1}(\beta)-A / F_{\mathrm{s}}\right)+\psi(N) \\
q_{2}(k+1)= & q_{2}(k)+T\left(A / F(k)-A / F_{\mathrm{s}}-r_{2}(k)\right) \\
q_{1}(k+1)= & q_{1}(k)+T\left(T_{\mathrm{b}}(k)-r-r_{1}(k)\right) \\
x_{8}(k+1)= & x_{7}(k) \\
T_{\mathrm{b}}(k)= & x_{8}(k) \\
A(F(k)= & x_{6}(k)
\end{aligned}
$$

where $\tau_{\mathrm{s}}$ is the time constant of the EGO sensor. As a next step, $V_{L 1}$ and $V_{L 2}$ in (20) and(21) are simply extended and replaced with

$$
\begin{gathered}
V_{L 1}=V_{1}^{2}=\left(q_{1}+2.98\left(q_{2}+T\left(x_{2}+x_{3}+x_{4}+x_{5}\right)+\tau_{\mathrm{s}} x_{6}\right)+T\left(x_{7}+x_{8}\right)\right)^{2} \\
V_{L 2}=V_{2}^{2}=\left(\kappa\left(q_{2}+T\left(x_{2}+x_{3}+x_{4}+x_{5}\right)+\tau_{\mathrm{s}} x_{6}\right)+x_{1}\right)^{2}
\end{gathered}
$$

Then with the positive semi-definite Lyapunov function

$$
V_{L}(x)=V_{L 1}(x)+V_{L 2}(x)=V_{1}^{2}(x)+V_{2}^{2}(x) \geqslant 0 \quad \text { where } x=\left(p_{\mathrm{m}}, x_{1}, \ldots, x_{8}, q_{1}, q_{2}\right)
$$

difference equations (23), (24) and (25) are preserved, and accordingly, the same argument can be repeated to show asymptotic stability of $p_{\mathrm{m}}$ and $x_{1}$ in the manifold $W=\left\{x \mid \Delta V_{L}(x)=0\right\}$, 
which is equal to $Z=\left\{x \mid V_{L}(x)=0\right\}$. It follows therefore that $s_{1}(k)$ and $s_{2}(k)$, defined in Figure 9, both converge to constants. Since the linear subsystem of the model in Figure 9 is asymptotically stable, this guarantees that $x_{2}(k), \ldots, x_{8}(k)$ converge to constants. Hence, by (41) and (42), the integrator states converge as well. Thus the system is asymptotically stable in the manifold $Z$, and this proves stability in the sense of Lypaunov of the closed-loop system by Reference [8]. This then proves asymptotic stability in the sense of Lyapunov of the closed-loop system since all the states are bounded and approach $W$ by LaSalle's Theorem [17].

\subsection{Observer-based feedback implementation}

Since not all of the states are directly measurable, an observer is required in order to implement the feedback of Section 4.1. It is assumed that intake manifold pressure is measured by a MAP sensor. Since $x_{1}$ is simply a computation delay and is known, a Kalman filter is designed for the linear subsystem of Figure 9. The filter gain, $L$, is chosen to achieve an asymptotically stable error dynamics

$$
x_{\mathrm{e}}(k+1)=(A-L C) x_{\mathrm{e}}(k)
$$

where $x_{\mathrm{e}}=x-\hat{x}$. Then for any positive definite matrix $M$, there exists a unique positive definite matrix $Q[18]$ such that

$$
(A-L C)^{T} Q(A-L C)-Q=-M
$$

For the observer-based controller, (41) and (42) are now replaced with

$$
\begin{gathered}
V_{L 1}=V_{1}^{2}=\left(q_{1}+2.98\left(q_{2}+T\left(\hat{x}_{2}+\hat{x}_{3}+\hat{x}_{4}+\hat{x}_{5}\right)+\tau_{\mathrm{s}} \hat{x}_{6}\right)+T\left(\hat{x}_{7}+\hat{x}_{8}\right)\right)^{2} \\
V_{L 2}=V_{2}^{2}=\left(\kappa\left(q_{2}+T\left(\hat{x}_{2}+\hat{x}_{3}+\hat{x}_{4}+\hat{x}_{5}\right)+\tau_{\mathrm{s}} \hat{x}_{6}\right)+x_{1}\right)^{2}
\end{gathered}
$$

In order to analyse the closed-loop stability properties, a candidate positive semi-definite Lyapunov function is chosen as

$$
V_{\mathrm{e}}(x)=x_{\mathrm{e}}^{T} Q x_{\mathrm{e}} \geqslant 0 \quad \text { where } x=\left(p_{\mathrm{m}}, x_{1}, \ldots, x_{8}, q_{1}, q_{2}, \hat{x}_{2}, \ldots, \hat{x}_{8}\right)
$$

so that the difference equation, $\Delta V_{\mathrm{e}}(x(k))$, is negative semi-definite:

$$
\begin{aligned}
\Delta V_{\mathrm{e}}(x(k)) & =V_{\mathrm{e}}(x(k+1))-V_{\mathrm{e}}(x(k))=x_{\mathrm{e}}^{T}(k+1) Q x_{\mathrm{e}}(k+1)-x_{\mathrm{e}}^{T}(k) Q x_{\mathrm{e}}(k) \\
& =x_{\mathrm{e}}^{T}(k)\left((A-L C)^{T} Q(A-L C)-Q\right) x_{\mathrm{e}}(k)=-x_{\mathrm{e}}^{T}(k) M x_{\mathrm{e}}(k) \leqslant 0
\end{aligned}
$$

In the manifold $Z_{\mathrm{e}}=\left\{x \mid V_{\mathrm{e}}(x)=0\right\}$, the closed-loop system is asymptotically stable in the sense of Lyapunov, as proven in the previous subsection. This proves stability around equilibria by Reference [8]. Then by LaSalle's Theorem [17], the states approach the largest positively invariant set contained in $W_{\mathrm{e}}=\left\{x \mid \Delta V_{\mathrm{e}}(x)=0\right\}$. Since $W_{\mathrm{e}}=Z_{\mathrm{e}}$ from (48) and (49), it follows that the closed-loop system is asymptotically stable in the sense of Lyapunov. 


\section{PERFORMANCE ANALYSIS}

\subsection{Parameter design}

This subsection presents a way to select the parameters $\kappa, c_{1}$ and $c_{2}$. In the nominal case, that is, if the effective valve area $\beta$ is well within its constraint, condition (39) becomes

$$
\left|1-\kappa T W_{\mathrm{c}}\left(p_{\mathrm{m}}, N\right) \cdot \beta_{\Delta V_{L}=0}\right|=\left|1-\kappa \frac{-\psi(N)+r}{410.86}\right|<1
$$

and, since the static reference torque $r$ is a function of primary throttle angle and engine speed, $\kappa$ is scheduled as

$$
1-\kappa(\phi, N) \frac{-\psi(N)+r(\phi, N)}{410.86}=0.1
$$

in order to maintain condition (39). This will allow a consistent fuel convergence rate over the various operating points when $\Delta V_{L}$ is close to zero. As a next step, $c_{1}$ and $c_{2}$ are designed to shape the sensitivity function of the system's linearization about equilibria. For this purpose, the engine model and the observer-based controller are linearized at a nominal operating point, and $c_{1}$ and $c_{2}$ are tuned to minimize the cost

$$
J_{\mathrm{c}}=\sum_{k=1}^{n} \mathrm{e}^{w} \times \sigma\left(S_{k}\right)
$$

where, $\sigma\left(S_{k}\right)$ is the maximum singular value of the input sensitivity function, sampled at discrete points between 0 and one-half of the Nyquist frequency $(\pi / T), n$ is the number of sample points, and $w$ is a weight which was chosen to be 10 . In this way, the sensitivity function is shaped to be

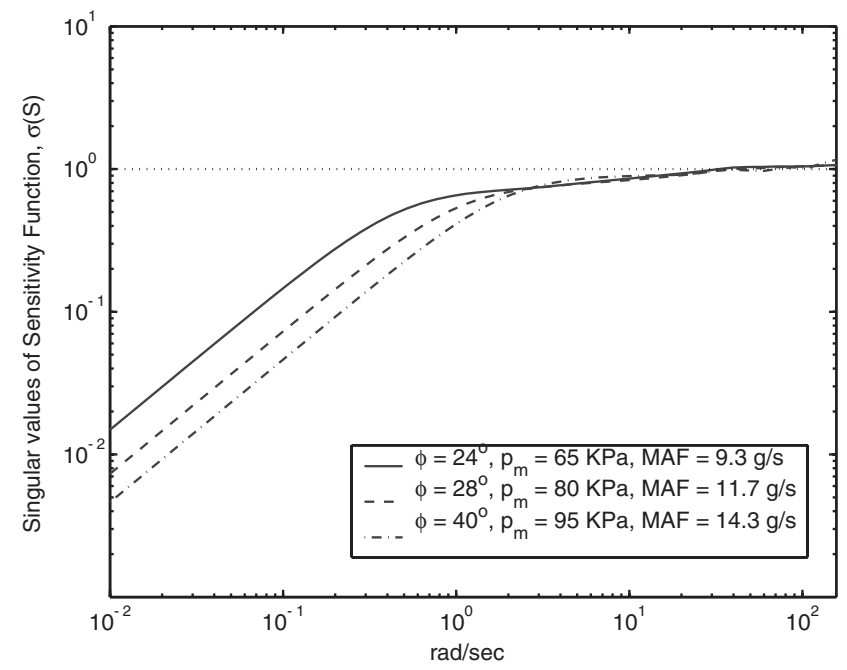

Figure 12. Singular values of input sensitivity functions at engine speed 1500 RPM; MAF represents mass air flow rate into the cylinder. 
below 1 over the specified frequency range, while the closed-loop bandwidth increases as much as possible.

As an example, at a constant engine speed of $1500 \mathrm{RPM}$, primary throttle angle equal to $25^{\circ}$ and effective valve area factor equal to $0.7, c_{1}$ and $c_{2}$ were both tuned to 0.048 . Figure 12 shows the maximum singular values of the sensitivity function at different primary throttle angles that are obtained with this method. It is seen that the sensitivity functions are nearly below 1 , but degrade as manifold pressure decreases. This is because the air charge actuator begins to lose authority over the air flow as manifold pressure decreases to $50 \mathrm{kPa}[5,3]$.

\subsection{Simulations}

The performance of the controller designed above was first evaluated through the mean-value model. The time constant, $\tau_{\mathrm{r}}$, of the torque reference model was set to 0.05 . The stoichiometric air-fuel ratio, $A / F_{\mathrm{s}}$, is set to 14.6 , and the engine speed was held constant at $1500 \mathrm{RPM}$.

The torque and $A / F$ responses were compared to the conventional engine, with fuel managed by a standard feedforward plus PI controller. The feedforward signal was generated in the usual
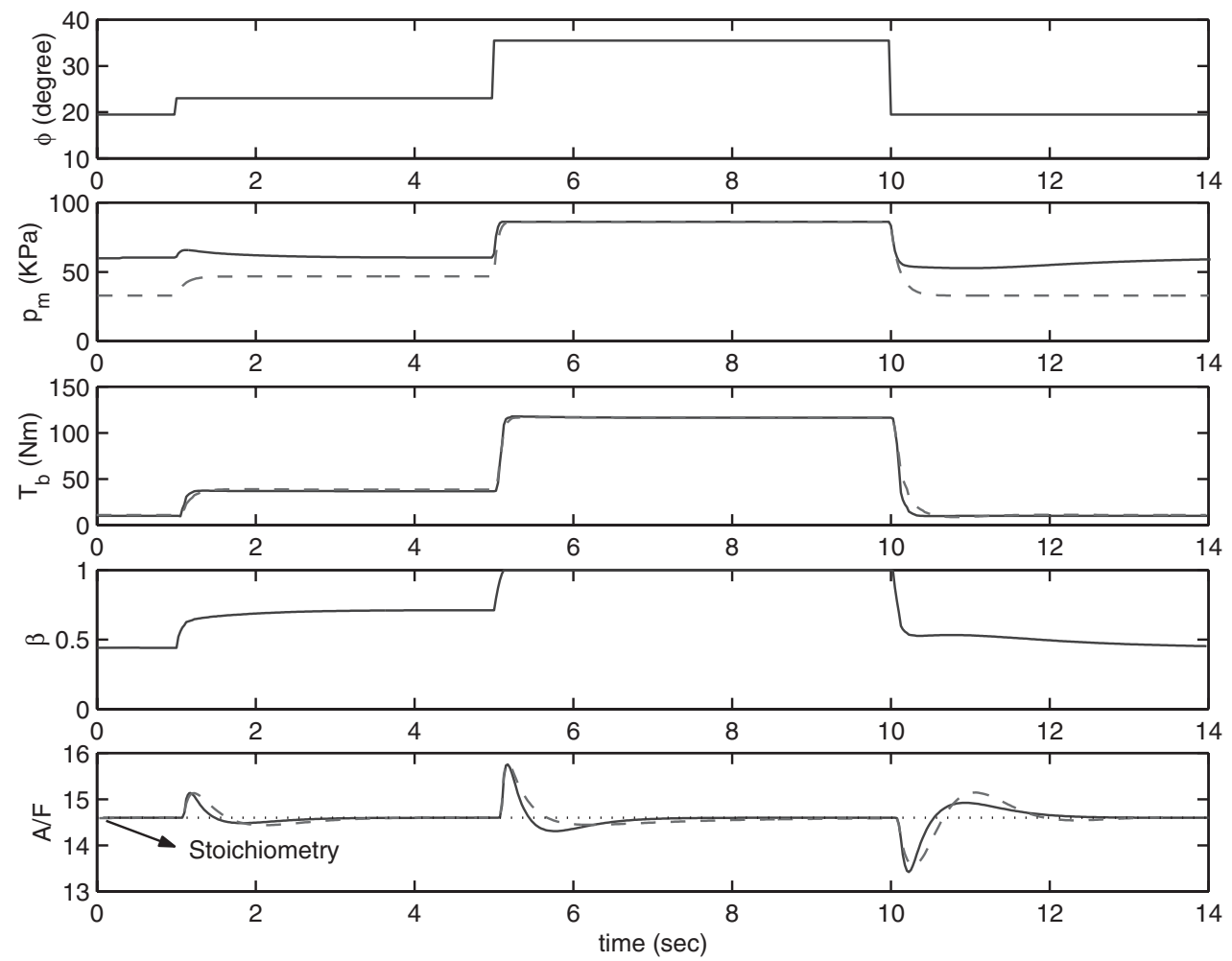

Figure 13. Simulation results with mean-value model at constant engine speed 1500 RPM. Solid line represents engine with joint air and fuel control and the dashed line the conventional engine with a feedforward plus PI controller. The results demonstrate higher intake manifold pressure achieved at low loads (hence, better fuel economy through reduced pumping losses), while achieving $A / F$ and torque responses comparable to a conventional engine. 


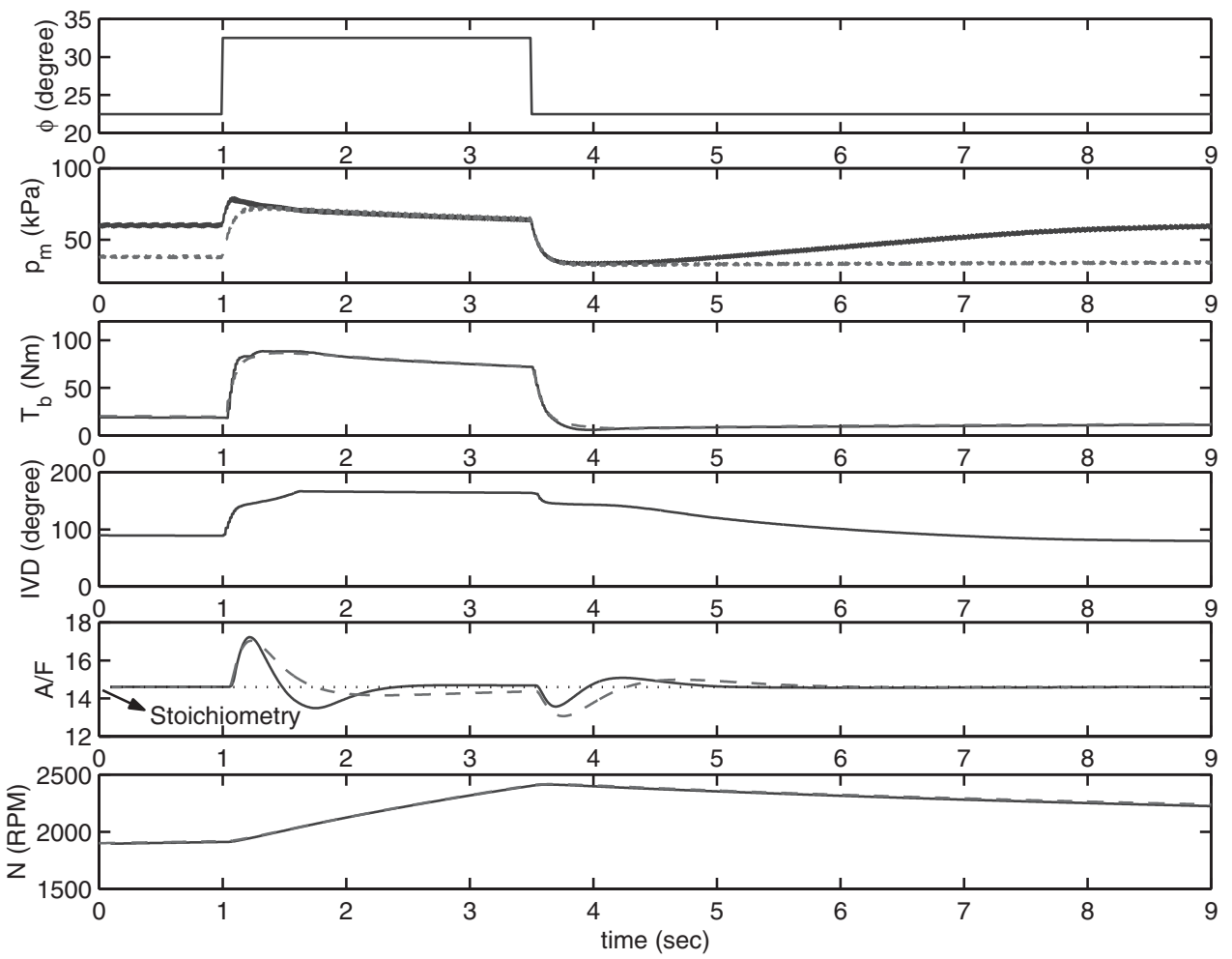

Figure 14. Simulation results with the detailed intake stroke model, fuel puddle dynamics and varying engine speed. Solid line represents engine with joint air and fuel control and the dashed line the conventional engine with a feedforward plus PI controller. Note that the variation in manifold pressure during an intake event is captured in this simulation.

way, and the PI gain was chosen so that $A / F$ excursions are minimized. The results, displayed in Figure 13, show that the engine with joint air and fuel control achieves similar torque response to the conventional engine. At 2 seconds, $a+3.5^{\circ}$ step change was given at a primary throttle angle $19.5^{\circ}$, and it is seen that the effective valve area slowly increases to smooth the air flow change caused by the driver, resulting in superior $A / F$ performance over the conventional engine. At 5 and 10 seconds, $+12.5^{\circ}$ and $-16^{\circ}$ step changes were given. With the throttle step increase, the effective valve area factor reaches its maximum constrained value. In each case, for the engine with joint air and fuel control, the $A / F$ response has a faster convergence rate to stoichiometry than that of the conventional engine. However, there is a slightly larger undershoot at tip-out. Figure 13 also displays the intake manifold pressure. The possibility of controlling the cylinder air charge process has resulted in the ability to maintain a higher manifold pressure than that of the conventional engine, yielding a potential reduction of pumping losses at low primary throttle angles.

In the second simulation, shown in Figure 14, the performance of the controller was evaluated on the more detailed intake stroke model in Section 2. In addition, the fuel puddle dynamics developed in Reference [19] is included in the fuel path after the injection delay, and the engine 
speed was allowed to vary through a rotational dynamics model. Instead of an MAP sensor, an MAF sensor is used to measure the mass air flow rate into throttle body, and the algorithm in Reference [16] is employed to estimate the intake manifold pressure; see Appendix A for details.

In this simulation, the physical variable IVD is plotted instead of the virtual control variable, $\beta$; the effective valve area factor, $\beta$, exceeds the constraint from 1.6 to 3.5 seconds. It is seen that the controller achieves a torque response similar to that of the conventional engine, but superior $A / F$ performance and higher intake manifold pressure.

\section{CONCLUSIONS}

In this paper, a discrete-time, nonlinear controller was developed for joint air and fuel management in a SI engine with variable valve timing. A mean-value model was derived from a detailed intake stroke model, and used for the control design. The control law was based on a conceptually simple control Lyapunov function, and includes a recovery scheme for integrator anti-wind-up. The performance of the closed-loop system was evaluated via simulation on the detailed intake stroke model. It was seen that joint air and fuel management in a SI engine has the potential to achieve a faster $A / F$ convergence rate to stoichiometry and lower pumping losses than a conventionally controlled engine, with a torque response that is similar to that of a conventionally controlled engine. This implies that improved fuel economy and emissions performance can be obtained through joint air and fuel control without losing drivability.

\section{ACKNOWLEDGEMENTS}

The authors thank J. Cook of Ford Motor Company for helpful discussions. The work was supported by an NSF GOALI grant, ECS-9631237, with matching funds from Ford Motor Company.

\section{APPENDIX A: INTAKE MANIFOLD PRESSURE ESTIMATE VIA MAF SENSOR}

The algorithm in Reference [16], which estimates the intake manifold pressure from direct measurement of $W_{\phi}$ from the MAF sensor (hot-wire anemometer), is briefly summarized here. The sensor dynamics is approximated as a first-order lag with time constant $\tau_{\mathrm{m}}(=0.13 \mathrm{~s})$ :

$$
m(k+1)=\left(1-\frac{T}{\tau_{\mathrm{m}}}\right) m(k)+\frac{T}{\tau_{\mathrm{m}}} W_{\phi}\left(p_{\mathrm{m}}(k), N\right)
$$

where $m$ represents the sensor's output (in $\mathrm{g} / \mathrm{s}$ ). The estimate of intake manifold pressure, $\hat{p}_{\mathrm{m}}$, is

$$
\begin{aligned}
\hat{p}_{\mathrm{m}}(k+1) & =\hat{p}_{\mathrm{m}}(k)+\frac{R T_{\mathrm{m}}}{V_{\mathrm{m}}} T\left(W_{\phi}\left(p_{\mathrm{m}}(k), N\right)-\operatorname{sat}_{0.1}^{1}(\beta) W_{\mathrm{c}}\left(\hat{p}_{\mathrm{m}}(k), N\right)\right) \\
& =\hat{p}_{\mathrm{m}}(k)+\frac{R T_{\mathrm{m}}}{V_{\mathrm{m}}} T\left(\frac{\tau_{\mathrm{m}}}{T} m(k+1)-\left(\frac{\tau_{\mathrm{m}}}{T}-1\right) \quad m(k)-\operatorname{sat}_{0.1}^{1}(\beta) W_{\mathrm{c}}\left(\hat{p}_{\mathrm{m}}(k), N\right)\right)
\end{aligned}
$$


To remove the $m(k+1)$ term, a new variable $\chi$ is defined as

$$
\chi(k)=\hat{p}_{\mathrm{m}}(k)-\frac{R T_{\mathrm{m}}}{V_{\mathrm{m}}} \tau_{\mathrm{m}} m(k)
$$

This yields

$$
\begin{aligned}
\chi(k+1) & =\chi(k)+\frac{R T_{\mathrm{m}}}{V_{\mathrm{m}}} T\left(m(k)-\operatorname{sat}_{0.1}^{1}(\beta) W_{\mathrm{c}}\left(\hat{p}_{\mathrm{m}}(k), N\right)\right) \\
\hat{p}_{\mathrm{m}}(k) & =\chi(k)+\frac{R T_{\mathrm{m}}}{V_{\mathrm{m}}} \tau_{\mathrm{m}} m(k)
\end{aligned}
$$

\section{APPENDIX B: NOMENCLATURE}

$A / F$
$A / F_{\mathrm{S}}$
$A_{\mathrm{V}}$
$A_{\phi}$
$F_{\mathrm{c}}$
IVD
IVL
IVO
$J$
$L_{\mathrm{V}_{i}}$
$N$
$R$
$S_{k}$
$T$
$T_{\mathrm{b}}$
$T_{\mathrm{c}}$
$T_{\mathrm{m}}$
$V_{\mathrm{c}_{i}}$
$V_{\mathrm{cl}}$
$V_{\mathrm{d}}$
$V_{\mathrm{m}}$
$W_{\mathrm{a}}$
$W_{\mathrm{c}}$
$W_{\mathrm{c}_{i}}$
$W_{\phi}$
$m_{\mathrm{a}}$
$m_{\mathrm{a}_{i}}$
$p_{\mathrm{c}_{i}}$
$p_{\mathrm{m}}$

$A / F$

$A / F_{\mathrm{s}}$

$A_{\mathrm{v}}$

$A_{\phi}$

IVD

IVL

$J$

$L_{\mathrm{v}_{i}}$

$R$

$S_{k}$

$T$

$T_{\mathrm{b}}$

$T_{\mathrm{m}}$

$V_{\mathrm{c}_{i}}$

$V_{\mathrm{cl}}$

$V^{2}$

$W_{\mathrm{a}}$

$W_{\mathrm{c}}$

$W_{\phi}$

$m_{\mathrm{a}}$

$p_{\mathrm{c}_{i}}$

$p_{\mathrm{m}}$ air-fuel ratio

stoichiometric air-fuel ratio $(=14.64)$

effective area of intake valve $\left(\mathrm{m}^{2}\right)$

effective area of throttle body $\left(\mathrm{m}^{2}\right)$

fuel injection rate $(\mathrm{g} / \mathrm{s})$

intake valve open duration (degrees)

intake valve lift (mm)

intake valve open timing (degrees)

engine inertia $\left(=0.34 \mathrm{Nm} \mathrm{s}^{2} / \mathrm{rad}\right)$

intake valve lift of $i$ th cylinder (mm)

engine speed (RPM)

specific gas constant $(=0.287 \mathrm{~J} / \mathrm{gK})$

sampled sensitivity function

time taken for intake event (s)

break torque $(\mathrm{Nm})$

cylinder wall temperature during intake event $(=370 \mathrm{~K})$

intake manifold temperature $(=316 \mathrm{~K})$

volume of $i$ th cylinder $\left(\mathrm{m}^{3}\right)$

cylinder clearance volume $\left(=4 \times 10^{-5} \mathrm{~m}^{3}\right)$

cylinder displacement volume $\left(=4 \times 10^{-4} \mathrm{~m}^{3}\right)$

volume of intake manifold $\left(=0.0025 \mathrm{~m}^{3}\right)$

mass air flow rate into cylinder of air flow actuated engine $(\mathrm{g} / \mathrm{s})$

mass air flow rate into cylinder of conventional engine $(\mathrm{g} / \mathrm{s})$

mass air flow rate into $i$ th cylinder $(\mathrm{g} / \mathrm{s})$

mass air flow rate into intake manifold $(\mathrm{g} / \mathrm{s})$

averaged mass air charge ( $\mathrm{g} /$ intake event)

mass air charge in $i$ th cylinder ( $\mathrm{g} /$ intake event)

pressure in $i$ th cylinder $(\mathrm{Pa})$

intake manifold pressure $(\mathrm{Pa})$ 
$p_{0}$

$r$

$t$

$\beta$

$\zeta$

$\theta$

$\phi$

$\tau_{\mathrm{m}}$

$\tau_{\mathrm{r}}$

$\tau_{\mathrm{s}}$

$\kappa, c_{1}, c_{2}$ atmospheric pressure $(100 \mathrm{kPa})$

reference torque $(\mathrm{Nm})$

time (s)

effective area factor of intake valve

inverted fuel injection rate $(\mathrm{s} / \mathrm{g}), 1 / F_{\mathrm{c}}$

crank-angle (degrees)

primary throttle angle (degrees)

time constant of MAF sensor $(=0.13 \mathrm{~s})$

time constant of reference torque $(=0.05 \mathrm{~s})$

time constant of EGO sensor $(=0.20 \mathrm{~s})$

control parameters

\section{REFERENCES}

1. Emtage AL, Lawson PA, Passmore MA, Lucas GG, Adcock PL. The development of an automotive drive-by-wire throttle system as a research tool. SAE Paper, No. 910081, 1991.

2. Bidan P, Boverie S, Chaumerliac V. Nonlinear control of a spark-ignition engine. IEEE Transactions on Control Systems Technology 1995; 3(1):4-13.

3. Stefanopoulou AG. Modeling and control of advanced technology engines. Ph.D. Thesis, University of Michigan, 1996.

4. Ashhab MS, Stefanopoulou AG, Cook JA, Levin M. Camless engine control for robust unthrottled operation. $S A E$ Paper, No. 981031, 1998.

5. Stefanopoulou AG, Cook JA, Grizzle JW, Freudenburg JS. Joint air-fuel ratio and torque regulation using secondary cylinder air flow actuators. ASME Journal of Dynamics Systems, Measurement, and Control, to appear (see also Stefanopoulou, AG, Grizzle, JW, Freudenburg, JS. Engine air-fuel ratio and torque control using secondary throttles. Proc. IEEE Conference Decision and Control, Orlando, 1994; 2748-2753).

6. Vogel O, Roussopoulos K, Guzzella L, Czekaj J. Variable valve timing implemented with a secondary valve on a four cylinder SI engine. 1997 Variable Valve Actuation and Power Boost SAE Special Publications, Vol. 1258 (970335) February 1997; 51-60.

7. Kang JM. Advanced Control For Fuel Economy and Emissions Improvement in Spark Ignition Engines. Ph.D. Thesis, University of Michigan, 2000.

8. Grizzle JW, Kang J-M. Discrete-time control design with positive semi-definite Lyapunov functions. Systems \& Control Letters 2001; 43:287-292.

9. Ashhab MS, Stefanopoulou AG, Cook JA, Levin MB. Control-oriented model for camless intake process (part I). ASME Journal of Dynamic Systems, Measurement, and Control, 2000; 122:122-130.

10. Heywood JB. Internal Combustion Engine. McGraw-Hill: New York, 1988.

11. Crossley PR, Cook JA. A nonlinear model for drivetrain system development. In IEE Conference 'Control 91', Vol. 2. March 1991; 921-925. IEE Conference Publication 332: Edinburgh, U.K.

12. Cook JA, Powell BK. Discrete simplified external linearization and analytical comparison of IC engine families. In Proceedings of American Control Conference, Minneapolis, June 1987; 325-333.

13. Yurkovich S, Simpson M. Comparative analysis for idle speed control: a crank-angle domain viewpoint. In Proceedings of American Control Conference, New Mexico, June 1997; 278-283.

14. Bitar S, Probst JS, Garshelis I. Development of a magnetoelastic torque sensor for formula 1 and champ car racing applications. SAE Paper, No. 2000-01-0085, 2000.

15. Sontag ED. A 'universal' construction of Artstein's theorem on nonlinear stabilization. Systems \& Control Letters 1989; 13:117-123.

16. Grizzle JW, Cook JA, Milam WP. Improved transient air-fuel ratio control using air charge estimator. In Proceedings of 1994 American Control Conference, Vol. 2. June 1994; 1568-1572.

17. Lakshmikantham V, Trigiante D. Theory of Difference Equation: Numerical Methods and Applications. Academic Press: New York, 1988.

18. Rugh WJ. Linear System Theory (2nd edn). Prentice-Hall: Englewood Cliffs, NJ, 1996.

19. Aquino CF. Transient A/F control characteristics of the 51 central injection engine. SAE Paper, No. 810494, 1981. 